10IKC-236

\title{
GEOLOGY AND EVALUATION OF THE K2 KIMBERLITE, KOIDU MINE, SIERRA LEONE, WEST AFRICA
}

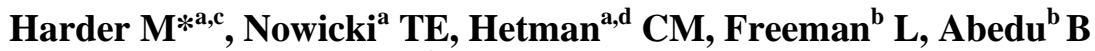 \\ ${ }^{a}$ Mineral Services Canada Inc., North Vancouver, Canada $;{ }^{b}$ Koidu Holdings S.A., Freetown, Sierra Leone; ${ }^{c}$ Currently with Tetra Tech Inc., \\ Vancouver, Canada $;{ }^{d}$ Currently with Northern Superior Resources Inc., Sudbury, Canada
}

\section{Introduction}

The K2 kimberlite is located on the Koidu Mine in the Kono District of eastern Sierra Leone, approximately $300 \mathrm{~km}$ east of the capital, Freetown (Fig. 1). The K2 pipe is approximately 0.5 hectares in size and is a smooth, steep sided pipe that tapers towards the south. K2 occurs on the Man Craton and is part of the Koidu kimberlite cluster, which also includes the K1 pipe, numerous blows, and four dyke systems. The Koidu cluster is part of a Jurassic province of kimberlites that includes the Tongo cluster as well as kimberlites in southeast Guinea and western Liberia (Skinner et al., 2004). A resource evaluation program conducted in 2008-2010 included a variety of evaluation techniques used to derive global estimates of diamond grade and value in support of a feasibility study on $\mathrm{K} 2$ and surrounding kimberlite bodies. A positive result has led to expansion of the mining project.

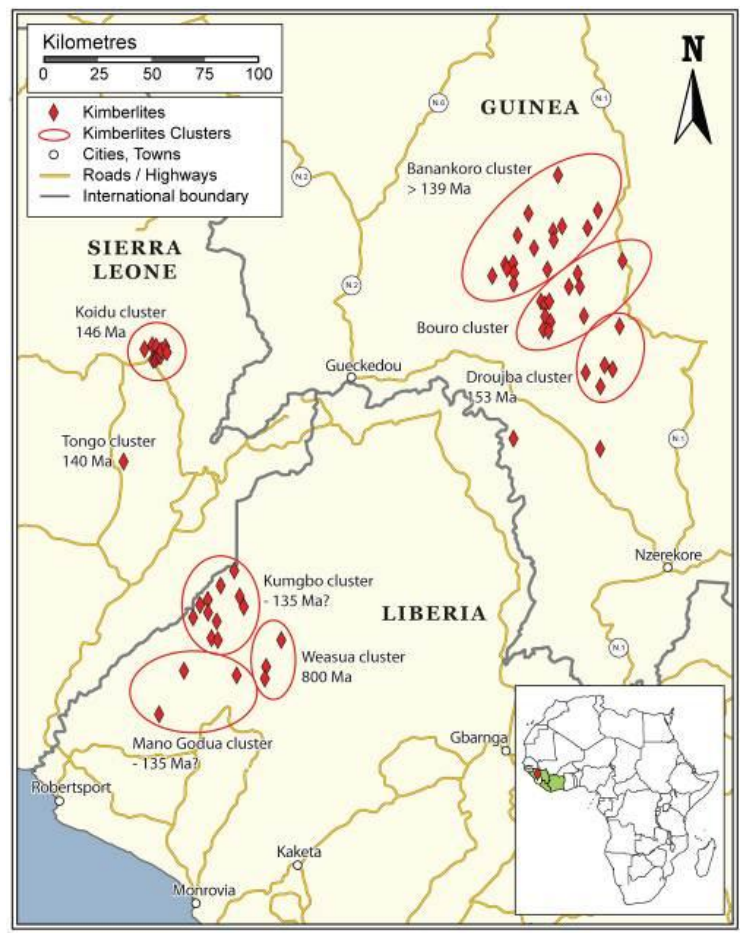

Figure 1: The K2 kimberlite is located in the Koidu cluster in eastern Sierra Leone, West Africa (after Skinner et al., 2004).

\section{Methods and Approach}

The geology and diamond content of K2 was evaluated using large diameter drilling, drillcore logging, microdiamond and indicator mineral abundance and composition studies; mapping of open pit exposures; targeted mining; three-dimensional geology modelling; and diamond grade and value estimation. Core logging established the internal geology of K2 down to depths of approximately $550 \mathrm{~m}$ below the pit floor surface. Microdiamond and indicator mineral results were used to confirm geological interpretations. The macrodiamond content was estimated through bulk sampling by large diameter drillholes (LDDH) and targeted mining. Detailed mapping of open pit exposures at the 325 masl level identified several distinctive geological units which were mined and processed separately. Three-dimensional (3D) geological models were created based on core drilling and mapping. These models were used in combination with bulk sampling results to define simplified grade domains for resource estimation.

\section{Geology of the K2 Kimberlite}

The Koidu kimberlites were emplaced into basement rocks dominated by Archean granitoid. The kimberlite was emplaced along a pre-existing kimberlite dyke system, "Dyke Zone A", and is associated with extensively brecciated and leached (porous) granite country rock with locally common "onion-skin boulders". These country rock features are likely related to early stages of kimberlite emplacement and pipe formation

$\mathrm{K} 2$ is infilled with variably sorted, inhomogeneous volcaniclastic kimberlite (VK) and locally common homogeneous coherent kimberlite $(\mathrm{CK})$. Numerous distinct and correlatable rock types of both $\mathrm{VK}$ and $\mathrm{CK}$ have been identified and assigned rock codes as a basis for 3D modelling. KIMB 1 is the volumetrically dominant pipe infill. It is shows significant internal variability and several sub-units have been defined (Fig. 2). KIMB1 is broadly characterised as massive volcaniclastic kimberlite (MVK; Sparks et al., 2006) or tuffisitic kimberlitic (TK; Clement and Skinner, 1985). It is typically pale to medium grey with a high proportion of xenoliths and an interclast matrix of fine grained kimberlitic constituents, pulverized granite, 


\section{$10^{\text {th }}$ International Kimberlite Conference, Bangalore - 2012}

serpentine, and clay. Olivine is pseudomorphed by serpentine and grain size is highly variable but most commonly fine- to medium- grained (after Field and Scott Smith, 1998). All KIMB1 sub-units fall into two main groups which are defined by variation in the size and characteristics of xenoliths. KIMB1B (Fig. 2) is characterized by $>5 \mathrm{~cm}$ xenoliths and is further subdivided into numerous sub-types. KIMB1A (Fig. 2) is less common than KIMB1B and is characterized by common $<5 \mathrm{~cm}$ xenoliths (rarely $>5 \mathrm{~cm}$ ). The distribution of country rock and kimberlite components is highly variable in KIMB1 and bedding and clast alignment are observed locally (Fig. 3).

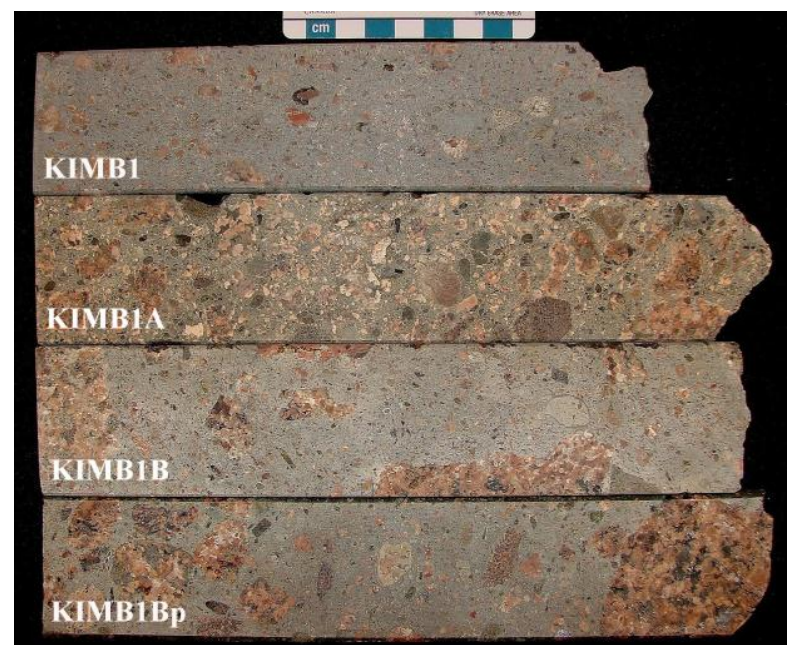

Figure 2: Photograph of drillcore slabs of KIMB1, highlighting the variability in kimberlite components and xenoliths. Pink fragments are granite xenoliths/xenocrysts. Olivine pseudomorphs are light greenish-grey to dark green.

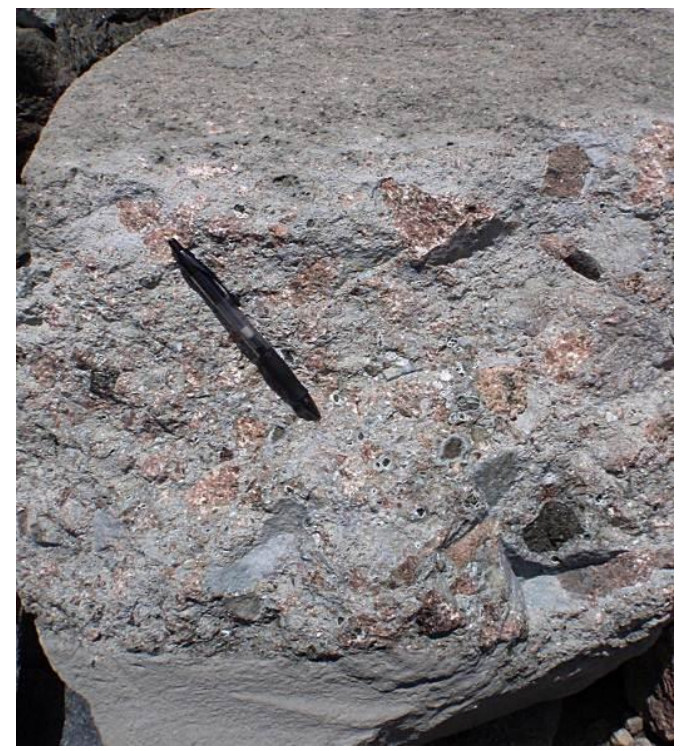

Figure 3: Photograph of KIMB1 (and KIMB3) highlighting bedding: rock units from top to bottom of photograph are: KIMB1A; KIMB1Bco; KIMB3. Pen is for scale.
Mappable sub-units of KIMB1B include: KIMB1Bco, characterised by common coarse- to very coarse-grained dark green altered olivine (Fig. 4); KIMB1Bgm, defined by the presence of abundant fine-grained granite in the matrix; KIMB1Bp, containing distinctive porous granite xenoliths (Fig. 2); KIMB1Bb, a zone with abundant large, commonly rounded ("onion skin") granite boulders; KIMB1Bm, marginal kimberlite material with a very high proportion of granitoid xenoliths.

Other VK units which have been assigned rock codes include KIMB3 and KIMB4. KIMB 3 is fine-grained with rare xenolithic material $>1 \mathrm{~cm}$ and occurs within KIMB1 both as large blocks and as irregular intervals, primarily between xenoliths. Contacts with KIMB1 can be both gradational and sharp (Fig. 3). KIMB4 is always observed adjacent to the pipe wall, frequently between the pipe contact and the main KIMB1 infill. KIMB4 is characterised by common distinctive aligned, shard-like granite xenocrysts.

KIMB2 is a texturally complex unit that displays transitional volcaniclastic to coherent textures. The grain size of olivine pseudomorphs in this material is more typical of CK units in $\mathrm{K} 2$.

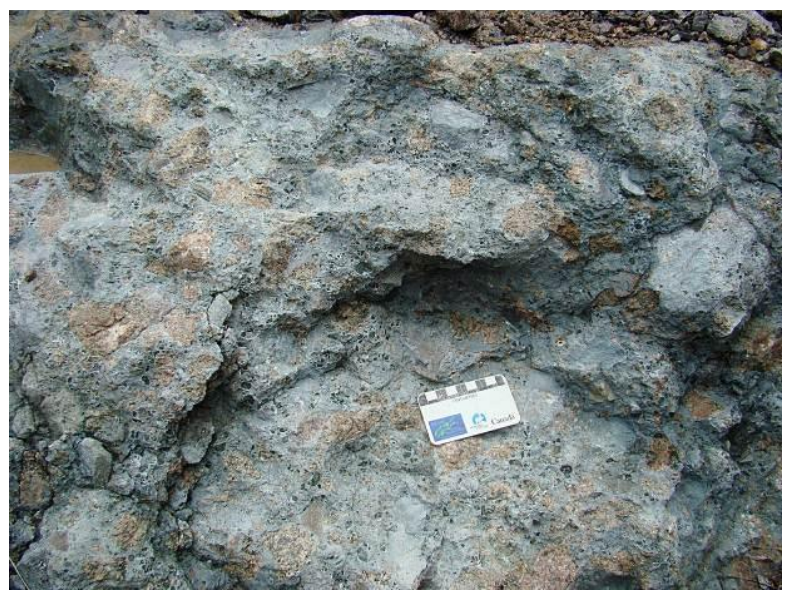

Figure 4: Photograph of open pit exposure of KIMB1Bco; dark green minerals are coarse- to very coarse-grained olivine (serpentine pseudomorphs). Pink areas are granite xenoliths.

$\mathrm{CK}$ is commonly observed throughout the $\mathrm{K} 2$ pipe as dykes, irregularly shaped intrusions and possible sills (Fig. 5). In most cases these are too irregular to map on the scale of drilling, but two larger mappable CK units have been defined (KIMB5 and KIMB6). CK in K2, as well as kimberlite magmaclasts within $\mathrm{VK}$, is classified as macrocrystic phlogopite $( \pm$ carbonate $)$ kimberlite. Proportions of mantle-derived minerals vary between individual intrusions and in some cases can be used for correlation. Contacts between CK and VK can be sharp to highly irregular, altered, and gradational/mixed (Fig. 5). 


\section{$10^{\text {th }}$ International Kimberlite Conference, Bangalore - 2012}

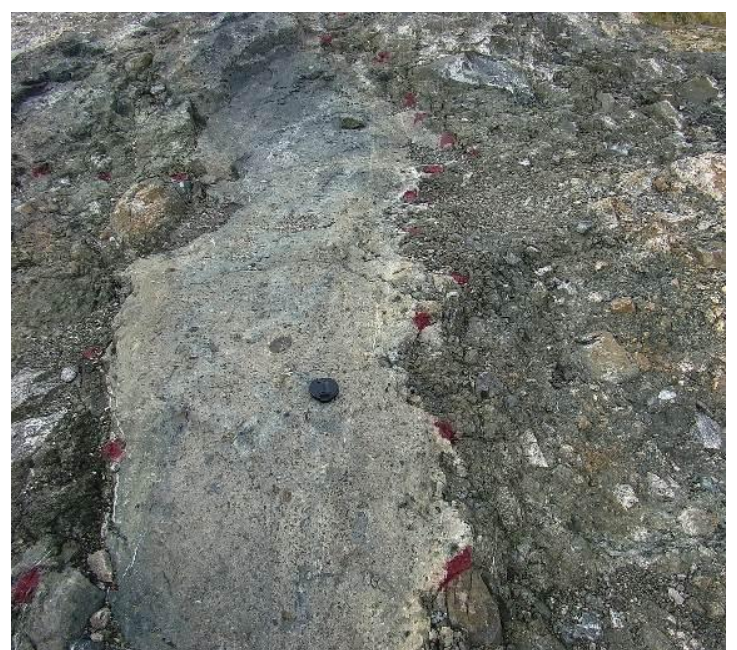

Figure 5: Open pit exposure of a dyke (centre of photo) intruding into KIMB1, showing complex, irregular contacts. Lens cap is for scale $(6 \mathrm{~cm})$.

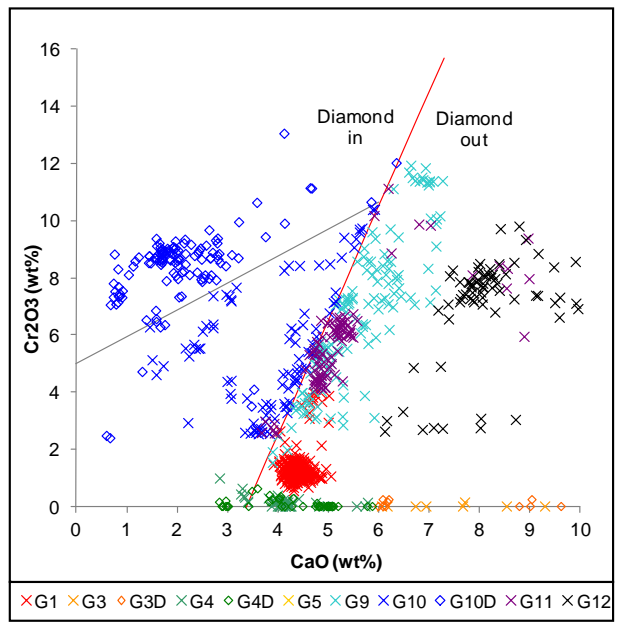

Figure 6: Garnet $\mathrm{Cr} 2 \mathrm{O} 3-\mathrm{CaO}$ plot showing compositional range in $\mathrm{K} 2$. Garnets are colour coded by paragenesis on the basis of the Grütter et al. (2004) classification. Red line: "Diamond in / diamond out" line of Gurney (1984); grey line: "graphite diamond constraint" of Grütter et al. (2006).

\section{Indicator mineral characteristics}

Samples representing KIMB1B, KIMB1A, and KIMB2 were analyzed by the Mantle Mapper ${ }^{\mathrm{TM}}$ method for indicator mineral abundance and composition. All samples yielded G10 garnets, including grains that range to high $\mathrm{Cr}$ contents and very low $\mathrm{Ca}$ contents (Fig. 6), suggesting sampling of highly depleted harzburgite / dunite that is prospective for peridotitic diamonds. The samples contain varying abundances of low-Cr garnets, dominated by megacrysts (G1) but including minor populations of eclogitic / websteritic grains (G3 and G4), some with elevated $\mathrm{Na}$ contents suggesting the presence of eclogitic diamonds. This is supported by commonly observed eclogite xenoliths in K2. KIMB1B and KIMB1A samples show similar indicator mineral characteristics, suggesting they are closely related and supporting combination into a single domain for resource estimation. KIMB2 shows similar compositional trends to KIMB1 but with a slightly higher proportion of peridotite and eclogite, more typical of CK observed at Koidu. This supports the interpretation of this unit forming by mixing of CK with VK.

\section{Large Diameter Drilling Bulk Sampling}

Bulk sampling by LDDH was conducted in two phases, with five holes completed in 2009 and six in 2010. LDDH were completed to depths of up to $350 \mathrm{~m}$ and were distributed across the surface of the pipe. To aid in geological interpretations, all LDDH were paired with core 'pilot' holes. A total of $\sim 1200$ tonnes of kimberlite were sampled by LDDH.

\section{Mapping and Targeted Mining}

Detailed mapping of the $\mathrm{K} 2$ open pit was conducted over the entire pit surface at the 325 masl level (Fig. 7). The complex pit floor geology was simplified into 7 bulk sample units' (BSU) for targeted mining. During mining, several of the BSU zones were further subdivided into separate stockpiles and processing units. The entire pit floor at the 325 masl level was mined with a 3-6 m lift.

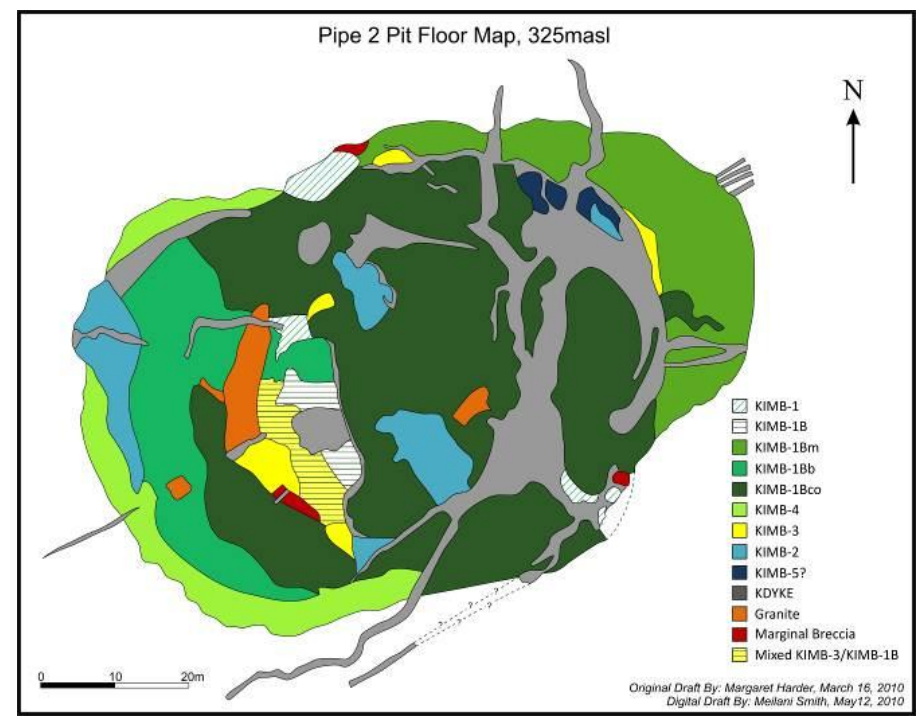

Figure 7: Geological map complied by mapping of open-pit exposures at the 325 masl level.

\section{Three-Dimensional Models}

The 3D geology model of $\mathrm{K} 2$ was constructed using information from drillcore and pit floor mapping. KIMB2 and KIMB3 units appear to be randomly distributed throughout the pipe and are volumetrically minor. Therefore these were included in the KIMB1 solid for modelling. In many cases the distribution of KIMB1 sub-units is either random or too complex to model with the current distribution of drillholes, and these rock types have also been included in KIMB1 for modelling. A plan view of the internal 3D geology model at the 325 masl level (Fig. 8) highlights the concentric deposition of kimberlite units within K2. Vertical sections of the K2 geology model are shown in Figure 9. 


\section{$10^{\text {th }}$ International Kimberlite Conference, Bangalore - 2012}

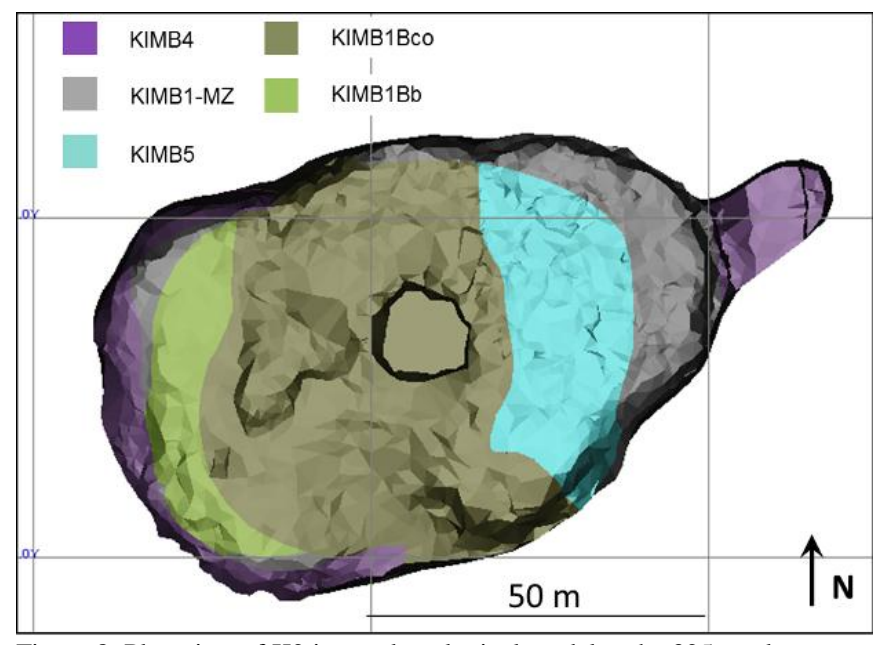

Figure 8: Plan view of K2 internal geological model at the 325 masl.

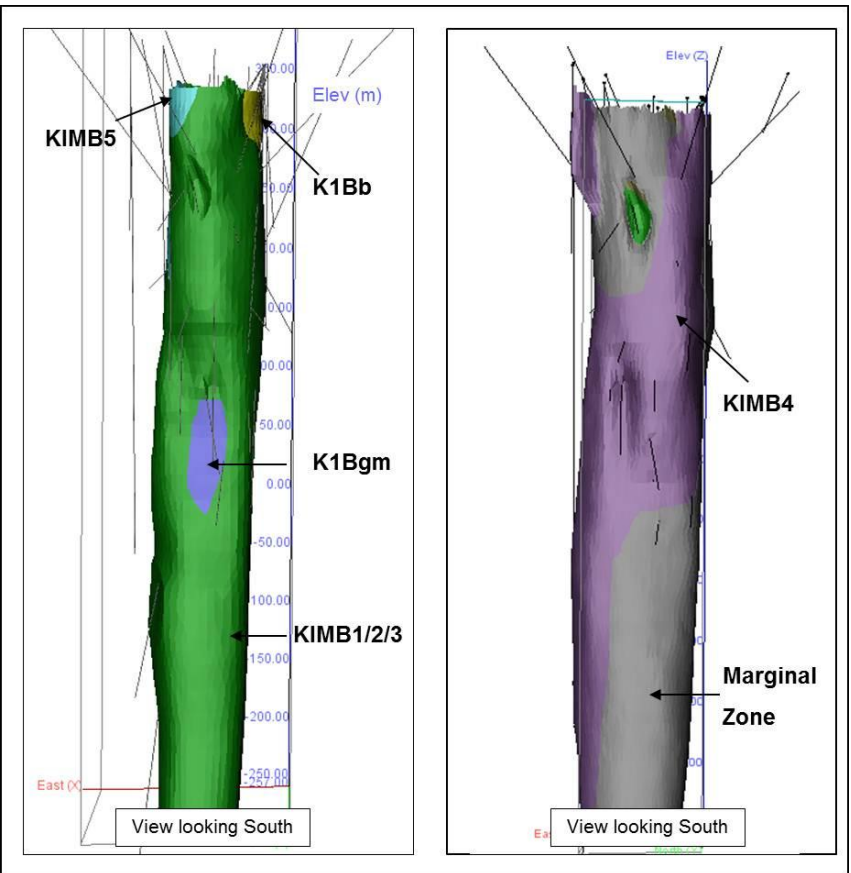

Figure 9: Vertical views of the K2 3D model. The green solid combines KIMB1 (including many sub-units), KIMB2, and KIMB3. The view on the right shows marginal kimberlite e units (KIMB4 and Marginal zone, see text below).

\section{Resource Estimation Results}

Diamond grade and value information was estimated using bulk sampling data from large diameter drilling and targeted mining. The complex internal geology of $\mathrm{K} 2$ was simplified into 10 grade domains based on geology and grade data (Fig. 10). The central core of K2 comprises predominantly KIMB1 rock types with varying proportions of CK (dykes and KIMB5), KIMB2, and KIMB3. These have been modelled as a single internally complex domain, comprising approximately $70 \%$ of the pipe volume.

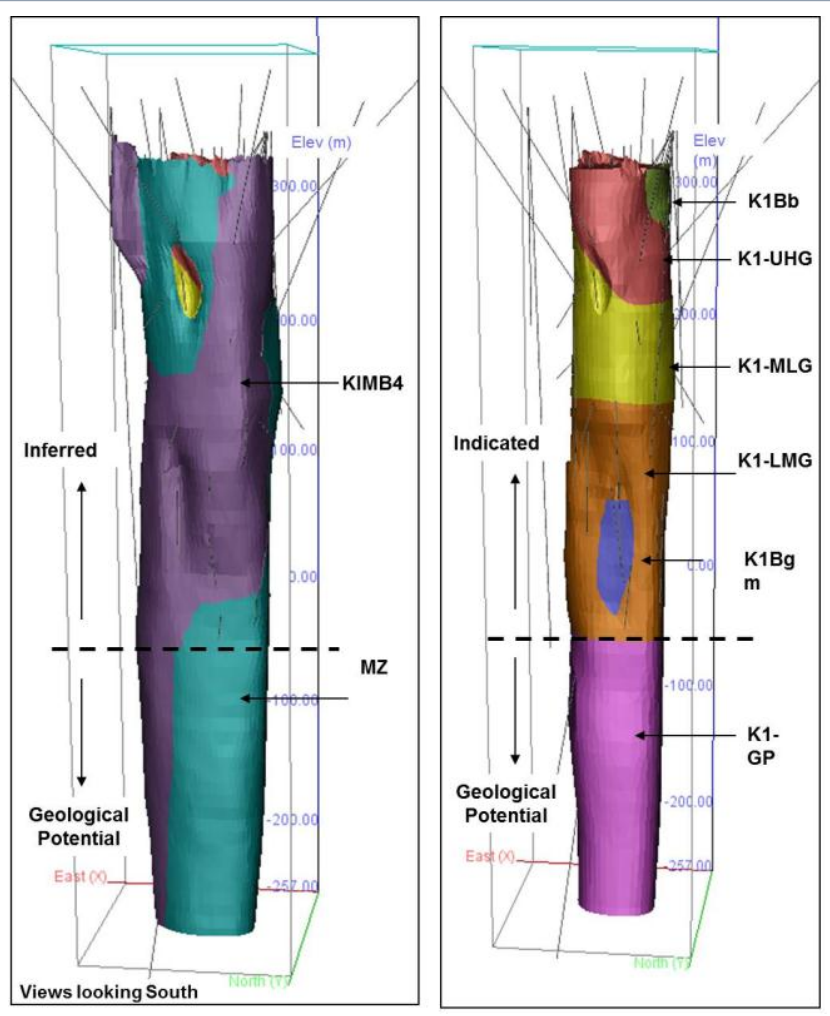

Figure 10: Vertical sections of domain models used for grade modelling. Indicated and inferred refer to resource classification confidence. Geological potential refers to portions of the pipe for which data are insufficient for resource estimation.

The KIMB1 domain has been subdivided into four main sub-domains: K1-UHG (KIMB1 upper high grade zone); K1-MLG (KIMB1 middle low grade domain); K1-LMG (KIMB1 lower moderate grade zone); and K1-GP (KIMB1 geological potential). The K1-UHG, K1-MLG, K1-LMG, and K1-GP units have horizontal to sub-horizontal surfaces based on a combination of geology, grade results, and the amount of drilling and grade sample information. Two smaller KIMB1 domains have also been defined: $\mathrm{K} 1 \mathrm{Bb}$ (KIMB1Bb - boulder zone); and K1Bgm (KIMB1Bgm granite dominated matrix); Two domains were defined on the pipe margins: K4 (KIMB4) and MZ ('Marginal Zone' material, comprising a variety of VK and CK units which cannot be correlated with confidence). The MZ domain forms a nearly complete shell around the KIMB1 core zone, whereas K4 occurs as discontinuous wedges on the outermost margin of the pipe.

Global estimates of the bulk density and diamond grade of each domain were derived using a large bulk density sampling database and available bulk sample data. Estimates were assigned a confidence classification (Fig. 10) based on the total size and distribution of samples as well as the degree and scale of internal geological variability. Diamond size distribution modelling was undertaken to assist in grade estimation, correct for variable recovery efficiencies in different sampling approaches and 


\section{$10^{\text {th }}$ International Kimberlite Conference, Bangalore - 2012}

Table 1: K2 bulk sample data by grade domains. $\mathrm{cpm}^{3}$ - carats per cubic metre; $\mathrm{cpt}$ - carats per tonne.

\begin{tabular}{|l|l|l|l|l|l|l|l|}
\hline Domain & K1 - UHG & K1-MLG & K1-LMG & K1Bb & MZ-U & K4-U & K1gm \\
\hline Basis for estimate & LDDH & LDDH & LDDH & BSU & BSU & BSU & LDDH \\
\hline Sample volume $\left(\mathbf{m}^{\mathbf{3}}\right)$ & 123 & 111 & 119 & 2987 & 4666 & 723 & 17 \\
\hline Domain bulk density $\left(\mathbf{g} / \mathbf{c m}^{3}\right)$ & 2.44 & 2.41 & 2.43 & 2.53 & 2.43 & 2.44 & 2.31 \\
\hline Sample grade $\left(\mathbf{c p m}^{\mathbf{3}}\right)$ & 1.34 & 0.73 & 1.00 & 0.55 & 0.83 & 0.67 & 0.45 \\
\hline Model grade $(\mathbf{c p m} \mathbf{3})$ & 1.17 & 0.57 & 0.82 & 0.56 & 0.86 & 0.74 & 0.34 \\
\hline Sample grade $(\mathbf{c p t})$ & 0.55 & 0.31 & 0.41 & 0.22 & 0.34 & 0.27 & 0.19 \\
\hline Modelled grade estimate $(\mathbf{c p t})$ & 0.48 & 0.24 & 0.34 & 0.22 & 0.36 & 0.30 & 0.15 \\
\hline
\end{tabular}

estimation of diamond value. Table 1 summarizes the bulk sample data and grade estimates for $\mathrm{K} 2$ resource domains.

\section{Discussion}

The conduit-filling VK deposits of $\mathrm{K} 2$ are interpreted as the products of at least two explosive eruptions. The kimberlite eruption initially exploited zones of weakness along the Dyke Zone A structure, which pre-dates the K2 pipe. KIMB4 is interpreted to be the oldest unit preserved in K2, observed as a discontinuous, thin rim around the edge of the pipe. KIMB1 material represents the main eruptive phase and resulted in significant excavation of KIMB4. The distribution of VK suggests both concentric deposition from the pipe margin towards the centre (as shown in Figures 8 and 9), and crude stratification creating sub-horizontal domains. Although most VK units are highly diluted, units near the pipe margins are often characterised by particularly high dilution, reflecting closer proximity to unstable pipe walls. Development of stratification within KIMB1 is indicated by the observation of several sub-horizontal kimberlite packages in drillcores and in LDDH grade results. Coherent kimberlite intrusions that cross cut K2 VK units, and therefore indicate post-pipe emplacement, are common and are volumetrically significant in some areas of the pipe. The highly variable contacts show local mixing between the intruding CK and the VK infill. The nature of these contacts indicates that the VK must have been poorly to unconsolidated at the time of intrusion of some CK units. Secondary alteration has modified the kimberlite mineralogically and to a lesser degree texturally.

The K2 pipe infill is characterised by many features consistent with the historical kimberlite classification 'tuffisitic kimberlite' (TK). However, K2 is internally highly complex and shows poorly- to locally welldeveloped bedding at both small and large scales. Preservation of stratification as well as concentric deposition of kimberlite units within K2 indicates that large scale fluidisation (as per Sparks et al., 2006 model) was not sustained.
The geological interpretation of $\mathrm{K} 2$ was fundamental to creation of 3D geology solids, and in turn the creation of 3D domain models used as a basis for grade estimation. The estimated grades and tonnages of the individual domains, as presented in Table 1, were used in a feasibility study and encouraging results have lead to expansion of the mine plan.

\section{References}

Clement, C.R. and Skinner, E.M.W. (1985): A textural-genetic classification of kimberlites. Trans. Geol. Soc. S. Afr. 88, pp. 403-409.

Field, M. and Scott Smith, B.H. (1998): Textural and genetic classification schemes for kimberlites: a new perspective. Extended abstracts of the Seventh International Kimberlite Conference, Cape Town, South Africa, pp. $214-216$

Grütter, H.S., Gurney, J.J., Menzies, A.H. and Winter, F. (2004). An updated classification scheme for mantle-derived garnet, for use by diamond explorers. Lithos, 77, 841-857.

Grütter, H.S., Latti, D. and Menzies, A.H. (2006). Cr-saturation arrays in concentrate garnet compositions from kimberlite and their use in mantle barometry. Journ. Petrol., 47, 801-820.

Gurney, J.J. (1984). A correlation between garnets and diamonds in kimberlites. In: Glover, J.E. and Harris, P.G. (Eds.), Kimberlite Occurrence and Origin: A basis for conceptual models in exploration, Geology Dept and University Extension, Univ. of W. Australia, Publ. 8., 143-166, Blackwell Scientific Publications, Perth.

Scott Smith, B.H., Nowicki, T.E., Russell, J.K., Webb, K.J, Hetman, C.M., Harder, M., Mitchell, R.H. (2008): Kimberlites: Descriptive Geological Nomenclature and Classification. 9th International Kimberlite Conference Extended Abstract No. 9IKC-A-00124, 2008

Skinner, E.M.W., Apter, D.B., Morelli, C., and Smithson, N.K. (2004): Kimberlites of the Man Craton, West Africa; in Proceedings of the 8th International Kimberlite Conference; Mitchell, R.H., Grutter, H.S., Heaman, L.M., Scott-Smith, B.H. and Stachel T., Editors. The C. Roger Clement Volume (1), Lithos 76, pp 233-259.

Sparks, R.S.J., Baker, L., Brown, R.J., Field, M., Schumacher, J., Stripp, G. and Walters, A. (2006): Dynamical Constraints on Kimberlite Volcanism. Journal of Volcanology and Geothermal Research 155, pp 1848 . 